\title{
Effect of Anthropogenic Activities on Patterns of Genetic Diversity in Symplocos racemosa Roxb. from Western Ghats, India
}

\author{
Sofia Banu, ${ }^{1,2}$ Rasika M. Bhagwat, ${ }^{1}$ Meena D. Lagu, ${ }^{1}$ Narendra Kadoo, ${ }^{1}$ \\ B. G. Kulkarni, ${ }^{3}$ and Vidya S. Gupta ${ }^{1}$ \\ ${ }^{1}$ Plant Molecular Biology Group, Biochemical Sciences Division, National Chemical Laboratory, Pune 411008, India \\ ${ }^{2}$ Department of Bioengineering and Technology, Gauhati University, Guwahati 781014, India \\ ${ }^{3}$ Botanical Survey of India, Western Circle, Pune 411001, India \\ Correspondence should be addressed to Vidya S. Gupta; vs.gupta@ncl.res.in
}

Received 30 September 2013; Revised 28 November 2013; Accepted 28 November 2013; Published 11 February 2014

Academic Editor: Alexandre Sebbenn

Copyright (c) 2014 Sofia Banu et al. This is an open access article distributed under the Creative Commons Attribution License, which permits unrestricted use, distribution, and reproduction in any medium, provided the original work is properly cited.

\begin{abstract}
The Western Ghats (WG) in India is recognized as one of the global biodiversity hotspots which have high proportion of endemic species and the medicinally important tree species. Due to medicinal importance and being found on the forest fringes, Symplocos racemosa Roxb. is highly susceptible to anthropogenic activities. The present study was undertaken to systematically analyze the effects of anthropogenic activities on the genetic diversity and population structure of $S$. racemosa and to generate preliminary data for conservation purposes. We analyzed the variation in intergenic sequences of chloroplast and mitochondrial genomes from seven sites of S. racemosa sampled from protected, semiprotected, and disturbed areas of WG. Total diversity was high although within-sites diversity was low. The protected sites were highly diverse, while the disturbed areas possessed less genetic diversity indicating the effect of anthropogenic activities.
\end{abstract}

\section{Introduction}

The Western Ghats (WG) in India is recognized as one of the world's ten most important biodiversity hotspots and has over 5000 species of flowering plants [1]. It covers an area of $160,000 \mathrm{~km}^{2}$, with an elevational range of $300-2700 \mathrm{~m}$ and a latitudinal extent of $12^{\circ}\left(8^{\circ} \mathrm{N}-20^{\circ} \mathrm{N}\right)$. The WG flora is characterized by many relictual species and a high proportion of endemic species [2]. However, due to the enormous demand for herbal products worldwide, there has been an indiscriminate extraction of the medicinally important plants from this region. As a result, WG is facing one of the largest demographic pressures of Southeast Asia [3] and this stresses the urgent need for revised protection measures for the WG/Sri Lanka hotspot.

The distribution of genetic variation within a species reflects both historical relationships among populations and ongoing processes of gene flow and isolation. As a consequence, genetic similarity observed between a given pair of populations may be either due to a recent common ancestry or the result of gene flow subsequent to population divergence. In many existing populations, genetic measures are based on genealogically unordered data that do not distinguish between these alternatives and the current population structure is typically assumed to reflect an equilibrium level of gene flow per generation [4]. However, this equilibrium perspective can be misleading, particularly for the species where recent history is a major determinant of population structure. In order to understand various selection pressures on the plants inhabiting these areas, it is important to analyze their genetic structure. It is known that the levels of genetic variation within and among natural populations provide fundamental information for both the understanding of the microevolutionary processes that bring about divergence 
within species and the establishment of efficient conservation practices for threatened ecosystems [5]. The use of molecular markers derived from different genomes provides a more complete description of population structure [6] and aids in identification of species, races, and populations for conservation programs [7]. In plants, the chloroplast (cp) and mitochondrial (mt) genomes evolve slowly compared to the nuclear genome and have low mutation and recombination rates [8]. Hence, for woody perennial plant species, nuclear genes provide little power for discrimination among populations because the majority of their diversity resides within populations [9]. In contrast, the cytoplasmic genomes of $c p$ and $\mathrm{mt}$ are often strongly differentiated among populations allowing identification of diverged populations [10].

Symplocos, a woody angiosperm of the family Symplocaceae, is relatively a large genus consisting of approximately 290 species, of which 68 have been reported from India [11]. A medicinally valued species of this genus, Symplocos racemosa Roxb., is found in forests of WG inhabiting an altitude range of $400-1000 \mathrm{~m}$. It is an evergreen moderate sized tree with leaves dark green and glabrous above, orbicular to elliptic lanceolate and subcoriaceous [12]. Its bark is cooling, mildly astringent, light, and useful in treating dropsy, elephantiasis, filaria, liver complaints, bowel complaints, eye diseases, ulcers, menorrhagia, and leucorrhoea [11]. Much attention has been paid to S. racemosa owing to its antifibrinolytic activity and inhibitory activity against snake-venom phosphodiesterase I [13] and some phenolic compounds as potential candidates for the therapy of arthritis [14]. Due to such high medicinal importance, the species is being rapidly extracted from its native habitats. Hence, we undertook this study to analyze systematically and examine the impact of habitat fragmentation on the genetic diversity of this species. Depending on the extent of anthropogenic disturbances, the seven collection sites in WG were classified as protected, semiprotected, and disturbed. We evaluated the genetic variation existing in intergenic sequences of $c p$ and mt DNA of $S$. racemosa to document the patterns of genetic diversity within and among the sites in the context of effect of habitat disturbance on its genetic diversity and need for conservation.

\section{Materials and Methods}

2.1. Study Areas. The study area comprised of seven sites from WG (Figure 1 and Table 1) spread over two states of India, namely, Karnataka and Maharashtra, and was divided into three groups. Group I represented the sites from protected areas like Agumbe (AGB), Bhagamandala (BHM), and Madikeri (MAD). Group II, defined as semiprotected areas, was comprised of protected forests disturbed to different extent and included Castle Rock (CAS) and Amboli (AMB). Similarly, Group III was comprised of sites from disturbed areas, Mahabaleshwar (MAH) and Tillari Dam (TIL). The sites were grouped on the basis of analysis of semiquantitative field observations. The rate of disturbance at each site was measured using different drivers of disturbances such as fire, grazing, paths construction, cutting trees, and tourism/collection, the details of which are mentioned in Table 2. Though all these areas were parts of protected forest zones mostly classified as forest reserves, human intervention as well as conservation methods varied necessitating an elaborate analysis of the anthropogenic activities on these forest regions.

2.2. Sampling. S. racemosa was collected from seven natural sites and the among-sites distances were more than $10 \mathrm{~km}$ as suggested by Nybom and Bartish [15]; the minimum and maximum aerial distances among the sites are $25 \mathrm{~km}$ and $648 \mathrm{~km}$, respectively. The collection sites were predetermined based on herbarium collections of Botanical Survey of India (Western Circle, Pune, India) (BSI) and field collections were made and observations recorded in collaboration with them. The number of plants collected per site ranged from five to twenty and a distance of about $10 \mathrm{~m}$ was maintained among the selected individuals to avoid sampling from the same clonal individuals. Leaf samples were collected from randomly selected trees, irrespective of their age or size. After collection, the leaves were cleaned, frozen immediately in liquid nitrogen, and stored at $-80^{\circ} \mathrm{C}$ till further processing.

2.3. DNA Extraction and PCR Amplification. Total genomic DNA was extracted using a modified cetyltrimethylammonium bromide (CTAB) method [16] and quantified on $0.8 \%$ agarose gel stained with ethidium bromide. Polymerase chain reaction (PCR) conditions were standardized for twenty pairs of universal primers representing various intergenic regions in cp and mt DNA as described by Demesure et al. [17], Dumolin-Lapegue et al. [18], and Chiang et al. [19]. Each $25 \mu \mathrm{L}$ reaction consisted of $60 \mathrm{ng}$ template DNA, $200 \mu \mathrm{M}$ of each dNTPs, $0.2 \mu \mathrm{M}$ of each primer, $1.5 \mathrm{mM} \mathrm{MgCl}_{2}, 0.8 \mathrm{U}$ of Taq DNA polymerase (Bangalore Genei, Bangalore, India), and 10X buffer provided by the manufacturer. The PCR amplifications were carried out in PTC 200 thermal cycler (MJ Research, Waltham, MA, USA) at initial denaturation $94^{\circ} \mathrm{C}$ for $5 \mathrm{~min}$, followed by 35 cycles of $94^{\circ} \mathrm{C}$ for $1 \mathrm{~min}$, $30 \mathrm{~s}$ at $50-63^{\circ} \mathrm{C}$ (depending upon the average annealing temperature of the primers used), and $2 \mathrm{~min}$ at $72^{\circ} \mathrm{C}$ with a final extension of $5 \mathrm{~min}$ at $72^{\circ} \mathrm{C}$. The PCR amplicons were separated by electrophoresis on $1 \%$ agarose gels in $0.5 \mathrm{X}$ Trisacetate-EDTA (TAE) buffer ( $\mathrm{pH} 8.0$ ). In all, ten $\mathrm{cp}$ and six mt DNA primers giving good amplicons during initial screening were considered for further study. For the present study PCRRFLP approach was used. For this analysis, $5 \mu \mathrm{L}$ of PCR product obtained using the selected primers was restricted separately with six different tetranucleotide specific restriction endonucleases (AluI, HaeIII, HhaI, MspI, RsaI, and TaqI) and four hexanucleotide specific restriction endonucleases (EcoRI, HinfI, HindIII, and XbaI) (Promega, USA) using 1-2 units of restriction enzyme in $1 \mathrm{X}$ restriction buffer (provided by the supplier) and incubating the reaction at $37^{\circ} \mathrm{C}\left(65^{\circ} \mathrm{C}\right.$ in case of TaqI) for 12-14 h. The restriction digests were resolved on $1.5 \%$ agarose gels (for fragments above $1.3 \mathrm{~kb}$ ) and on 2$3.5 \%$ MetaPhor agarose gels (Cambrex Bio Science, USA) (for fragments having size range of $75 \mathrm{bp}-1.3 \mathrm{~kb}$ ) in $0.5 \mathrm{X}$ tris 
TABLE 1: Sampling locations with global position and number of sampled individuals of Symplocos racemosa.

\begin{tabular}{|c|c|c|c|c|c|c|c|}
\hline States & Collection sites & Latitude & Longitude & Altitude (m) & Individuals sampled & Protection regime & Group \\
\hline \multirow{4}{*}{ Karnataka } & Agumbe (AGB) & N 13.50031 & E 75.08308 & 640 & 11 & $\mathrm{RF}$ & I \\
\hline & Bhagamandala (BHM) & N 12.38837 & E 75.48798 & 1273 & 8 & $\mathrm{RF}$ & I \\
\hline & Madikeri (MAD) & N 12.43467 & E 75.71656 & 1109 & 5 & $\mathrm{RF}$ & I \\
\hline & Castle Rock (CAS) & N 15.41788 & E 74.33014 & 600 & 20 & $\mathrm{RF}$ & II \\
\hline \multirow{3}{*}{ Maharashtra } & Amboli (AMB) & N 15.96496 & E 73.99225 & 912 & 15 & $\mathrm{RF}$ & II \\
\hline & Mahabaleshwar (MAH) & N 17.91670 & E 73.66670 & 1352 & 12 & ESA & III \\
\hline & Tillari Dam (TIL) & N 15.80165 & E 74.19120 & 790 & 20 & $\mathrm{RF}$ & III \\
\hline
\end{tabular}

Note. RF: reserved forest, ESA: ecosensitive area. Group I: protected area; Group II: semiprotected area; Group III: disturbed area.

TABLE 2: Sampling locations with drivers of disturbances and their weighted score.

\begin{tabular}{lccccccc}
\hline Location & Fire & Grazing & Paths & Cutting & Tourism/collection & Weighted score & Group \\
\hline AGB & 0 & 0 & 1 & 1 & 1 & 1 & 3 \\
BHM & 1 & 0 & 1 & 1 & 2 & I \\
MAD & 0 & 1 & 0 & 1 & 1 & 4 & I \\
CAS & 0 & 1 & 2 & 2 & 2 & 6 & I \\
AMB & 1 & 1 & 3 & 2 & 3 & II \\
MAH & 0 & 2 & 3 & 2 & 2 & II \\
TIL & 0 & 2 & 3 & 3 & III \\
\hline
\end{tabular}

For individual category score $0-3$ indicates 0 : no activity, 1: low activity, 2: moderate activity and 3: higher activity.

For total weighted score 0-4: no disturbance; 5-9: moderate disturbance 10->10: high disturbance.

Group I: protected area; Group II: semiprotected area; Group III: disturbed area.

borate EDTA-TBE ( $44.5 \mathrm{mM}$ Tris base; $44.5 \mathrm{mM}$ boric acid; $1 \mathrm{mM}$ EDTA) buffer. The agarose and MetaPhor agarose gels were stained with ethidium bromide and photographed using ImageMaster VDS gel documentation system (Amersham Biosciences, USA) under UV light.

2.4. Data Analysis. Definitions of chlorotypes and mitotypes were generated by combining the alleles observed using four and three primer pair-restriction endonuclease combinations (PECs) specific for cp and mt DNA, respectively. The diversity parameters $\left(H_{T}\right.$ : total diversity, $H_{S}$ : average intrapopulation diversity, and $G_{S T}$ : the level of population subdivision of diversity using unordered alleles) and the frequency of haplotypes were analyzed using the HAPLODIV program [20]. Similarly, the HAPLONST program [21] was used to calculate $N_{S T}$ (the level of population subdivision for ordered alleles) and $v_{T}$ and $v_{S}$ (analogues of $H_{T}$ and $H_{S}$ ). Likewise, PERMUT [21] was used to evaluate the differences between $G_{S T}$ and $N_{S T}$ values for statistical significance to identify the existence of geographical structure. Based on $H_{T}, H_{S}$, and $F_{S T}$ values, standardized $G_{S T}$ and Jost's $D$ values were calculated using Hedrick's [22] formula. Jost's $D$ can explain the differentiation based on mutation rate and allele identity [23].

$G_{S T}$ is defined as the proportion of genetic diversity that exists among populations [24] and is calculated from the total genetic diversity in the pooled population $\left(H_{T}\right)$ and the mean diversity within each population $\left(H_{S}\right)[24,25]$. A $G_{S T}$ value of "1" indicates that all populations are completely differentiated and all differences in haplotypic composition lie among populations rather than within. A $G_{S T}$ value of "0" indicates that all populations are the same and all differences in haplotypic composition lie within rather than among populations. Based on the previous observation, the diversity restricts the possible range of $G_{S T}$ [26]; the standardization of $G_{S T}$ was proposed by Hedrick [22] to account for the variation in the maximum obtainable $G_{S T}$. Based on Nei's [24] definition of $G_{S T}$, Hedrick defined the standardized $G_{S T}$, that is $G_{S T}^{\prime}$ [27]. The standardization ensures that $G_{S T}^{\prime}$ has an upper limit of 1 which is achieved in conditions (a) when populations have nonoverlapping sets of alleles (b) when all the populations are fixed for a single allele (within population diversity is zero) and in a condition when there are two or more different alleles over all populations. Strong effect of genetic drift and/or a low mutation rate finds expression in form of low values of $H_{S}$. Lowering of $H_{S}$ often leads to lowering of $D$, relative to $G_{S T}$. For practical purpose the observation is that $D$ is mostly larger than $G_{S T}$, owing to higher within population diversity, because in most of the analyzed studies the within population diversity is high, indicating that $G_{S T}$ underestimates among population differentiation. However, certain diversions have also been noted, stronger differentiation has been observed in case of $G_{S T}$ than D. As Hedrick's [22] $G_{S T}^{\prime}$ also suffers from the same underestimation in case the sampled population is small, it needs to be corrected and is termed as $G_{S T}^{\prime \prime}$ [27].

The unweighted pair group method with arithmetic Mean (UPGMA) dendrograms was constructed with coefficient of distances using MVSP for Windows (http://www .kovcomp.co.uk/mvsp/) with 1000 permutations to analyze 


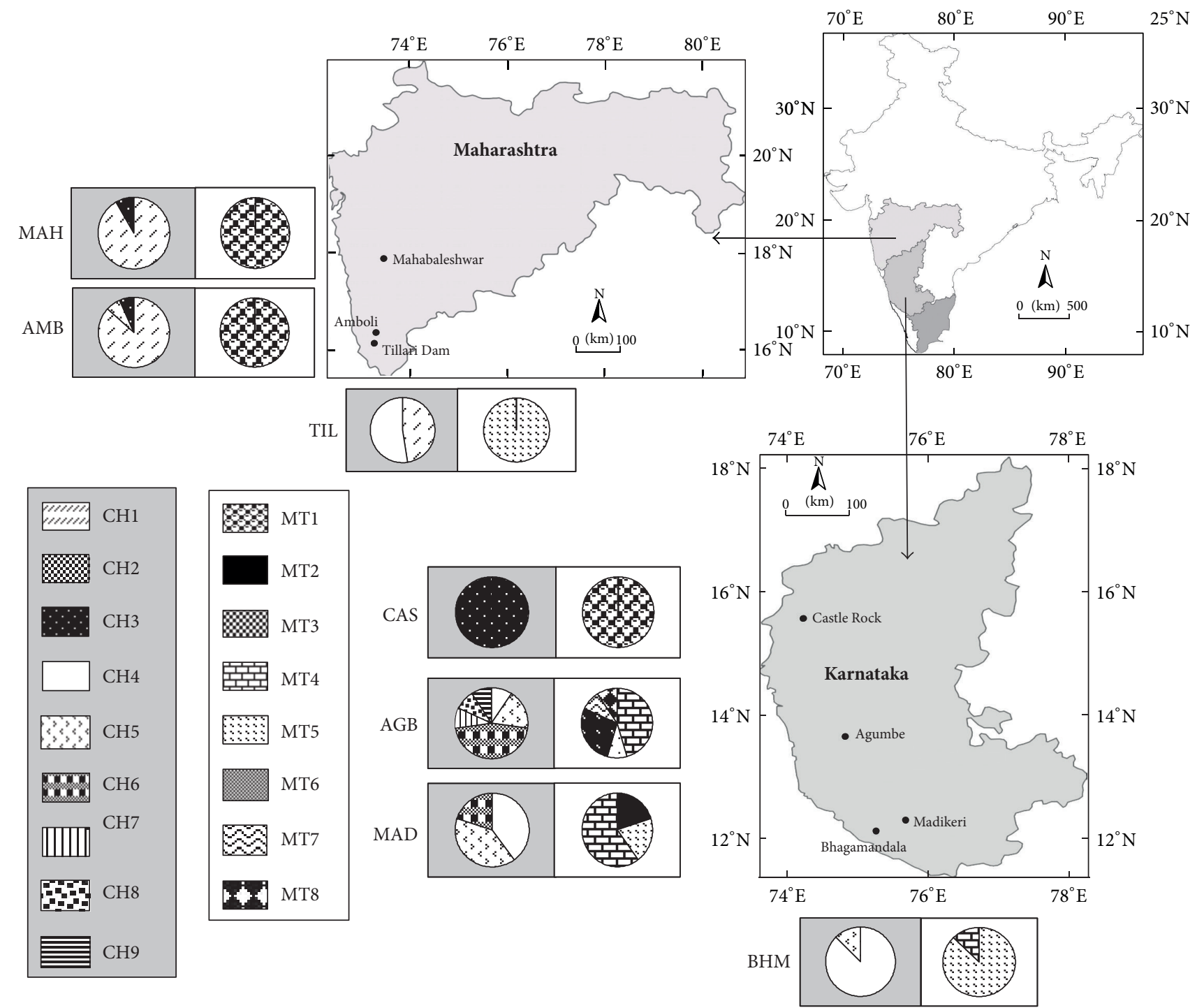

FIGURE 1: Sampling sites of Symplocos racemosa in Western Ghats with the states of Maharashtra and Karnataka projected out with distribution of chlorotypes (shaded boxes) and mitotypes (unshaded boxes) in these populations; CH1 to CH9: Nine chlorotypes; MT1 to MT8: eight mitotypes.

the relationships among the sites, for $\mathrm{cp}$ and $\mathrm{mt}$ data each. A minimum spanning network (MSN) among the haplotypes was constructed using ARLEQUIN version 3.11 [28] and visualized using TREEVIEW version 1.6.6 [29]. The influence of spatial separation on the degree of differentiation among the sites was investigated by calculating pairwise $G_{S T}$ and $N_{S T}$ values using the program DISTON (http://www.pierroton.inra.fr/genetics/labo/Software/Diston/index.html) and by plotting the means of these parameters against geographical distance classes. ARLEQUIN was used to partition the variance among the regions, sites and within sites, based on analysis of molecular variance (AMOVA). The AMOVA was performed in two ways: (i) the whole dataset with all the sites taken together and (ii) partitioning the sites in terms of their ecological status (protected, semiprotected, and disturbed).

\section{Results}

In case of cpDNA, the noncoding region between the psaA and $t r n S$ genes revealed polymorphism upon digestion with HaeIII, HhaI, HinfI, and RsaI enzymes. Similarly, in case of mtDNA, the nad7/2-nad7/3r region showed polymorphism upon digestion with AluI, HhaI, and RsaI (Table 3). From the initial screening, seven primer enzyme combinations (PEC) yielding unambiguous amplicons and digestion patterns were selected to analyze the genetic diversity among the 91 individuals from seven $S$. racemosa sites. Four of these patterns were $\mathrm{cp}$ specific, while three were mt specific. The size of the polymorphic fragments ranged from $75 \mathrm{bp}$ to $872 \mathrm{bp}$ for cpDNA and from $170 \mathrm{bp}$ to $740 \mathrm{bp}$ for mtDNA (Tables 3 and 4). The PEC psaA-trnS:HaeIII for cpDNA and nad7/2nad7/3r:HhaI for mtDNA showed the highest polymorphism 
TABLE 3: Distribution of the chlorotypes and mitotypes in seven populations of $S$. racemosa.

\begin{tabular}{|c|c|c|c|c|c|c|c|c|c|}
\hline \multirow{2}{*}{ Populations } & \multicolumn{4}{|c|}{ Karnataka } & \multicolumn{3}{|c|}{ Maharashtra } & \multirow{3}{*}{$\begin{array}{l}\text { Total } \\
(N)\end{array}$} & \multirow{3}{*}{ Frequency } \\
\hline & AGB & BHM & MAD & CAS & $\mathrm{AMB}$ & MAH & TIL & & \\
\hline Group & I & I & $\mathrm{I}$ & II & II & III & III & & \\
\hline \multicolumn{10}{|l|}{ Chlorotypes } \\
\hline $\mathrm{CH} 1$ & - & - & - & 18 & 13 & 11 & - & 42 & 0.462 \\
\hline $\mathrm{CH} 2$ & - & - & - & - & 1 & - & - & 1 & 0.011 \\
\hline $\mathrm{CH} 3$ & - & - & - & 2 & 1 & 1 & - & 4 & 0.044 \\
\hline $\mathrm{CH} 4$ & 1 & 7 & 2 & - & - & - & 20 & 30 & 0.330 \\
\hline $\mathrm{CH} 5$ & 2 & 1 & 2 & - & - & - & - & 5 & 0.055 \\
\hline $\mathrm{CH} 6$ & 5 & - & 1 & - & - & - & - & 6 & 0.066 \\
\hline $\mathrm{CH} 7$ & 1 & - & - & - & - & - & - & 1 & 0.011 \\
\hline $\mathrm{CH} 8$ & 1 & - & - & - & - & - & - & 1 & 0.011 \\
\hline $\mathrm{CH} 9$ & 1 & - & - & - & - & - & - & 1 & 0.011 \\
\hline Number of different chlorotypes & 6 & 2 & 3 & 2 & 3 & 2 & 1 & 9 & \\
\hline Haplotypes/individual & 0.55 & 0.25 & 0.60 & 0.10 & 0.20 & 0.17 & 0.05 & 0.10 & \\
\hline Haplotype diversity & $0.80 \pm 0.11$ & $0.25 \pm 0.18$ & $0.80 \pm 0.16$ & $0.19 \pm 0.11$ & $0.26 \pm 0.14$ & $0.17 \pm 0.13$ & $0.00 \pm 0.00$ & & \\
\hline \multicolumn{10}{|l|}{ Mitotypes } \\
\hline MT1 & - & - & - & 20 & 15 & 12 & - & 47 & 0.516 \\
\hline MT2 & - & - & 1 & - & - & - & - & 1 & 0.011 \\
\hline MT3 & - & 7 & 1 & - & - & - & 20 & 28 & 0.308 \\
\hline MT4 & 5 & 1 & 3 & - & - & - & - & 9 & 0.099 \\
\hline MT5 & 1 & - & - & - & - & - & - & 1 & 0.011 \\
\hline MT6 & 3 & - & - & - & - & - & - & 3 & 0.033 \\
\hline MT7 & 1 & - & - & - & - & - & - & 1 & 0.011 \\
\hline MT8 & 1 & - & - & - & - & - & - & 1 & 0.011 \\
\hline Number of different mitotypes & 5 & 2 & 3 & 1 & 1 & 1 & 1 & 8 & \\
\hline Haplotypes/individual & 0.45 & 0.25 & 0.60 & 0.05 & 0.07 & 0.08 & 0.05 & 0.09 & \\
\hline Haplotype diversity & $0.76 \pm 0.11$ & $0.25 \pm 0.18$ & $0.70 \pm 0.22$ & $0.00 \pm 0.00$ & $0.00 \pm 0.00$ & $0.00 \pm 0.00$ & $0.00 \pm 0.00$ & & \\
\hline
\end{tabular}

TABLE 4: Analysis of molecular variance (AMOVA) of S. racemosa populations.

\begin{tabular}{|c|c|c|c|c|c|}
\hline Source of variation & d.f. & SS & Variance components & Percentage variation & \\
\hline \multicolumn{6}{|c|}{ (a) AMOVA with all the populations taken together } \\
\hline \multicolumn{6}{|l|}{ cpDNA } \\
\hline Among populations & 6 & 106.508 & 1.367 & 74.32 & \multirow{2}{*}{$F_{S T}=0.743$} \\
\hline Within populations & 84 & 39.668 & 0.472 & 25.68 & \\
\hline \multicolumn{6}{|l|}{ mtDNA } \\
\hline Among populations & 6 & 68.802 & 0.877 & 69.26 & \multirow{2}{*}{$F_{S T}=0.693$} \\
\hline Within populations & 84 & 32.670 & 0.389 & 30.74 & \\
\hline \multicolumn{6}{|c|}{ (b) AMOVA with populations divided into three ecological groups (protected, semiprotected, and disturbed) } \\
\hline \multicolumn{6}{|l|}{ cpDNA } \\
\hline Among groups & 2 & 10.362 & 0.08294 & 21.05 & \multirow{3}{*}{$F_{S T}=0.668$} \\
\hline Among populations within groups & 4 & 9.064 & 0.18021 & 45.74 & \\
\hline Within populations & 84 & 10.992 & 0.13085 & 33.21 & \\
\hline \multicolumn{6}{|l|}{ mtDNA } \\
\hline Among groups & 2 & 12.330 & 0.10485 & 27.26 & \multirow{3}{*}{$F_{S T}=0.811$} \\
\hline Among populations within groups & 4 & 10.115 & 0.20731 & 53.89 & \\
\hline Within populations & 84 & 6.093 & 0.07254 & 18.86 & \\
\hline
\end{tabular}




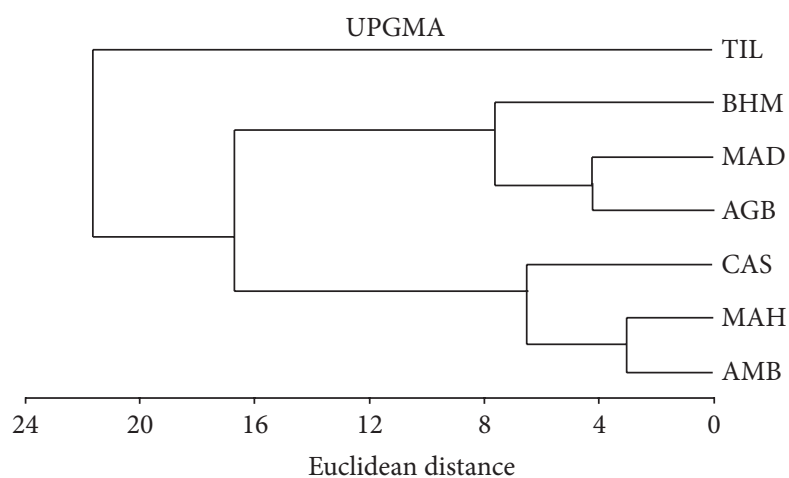

(a)

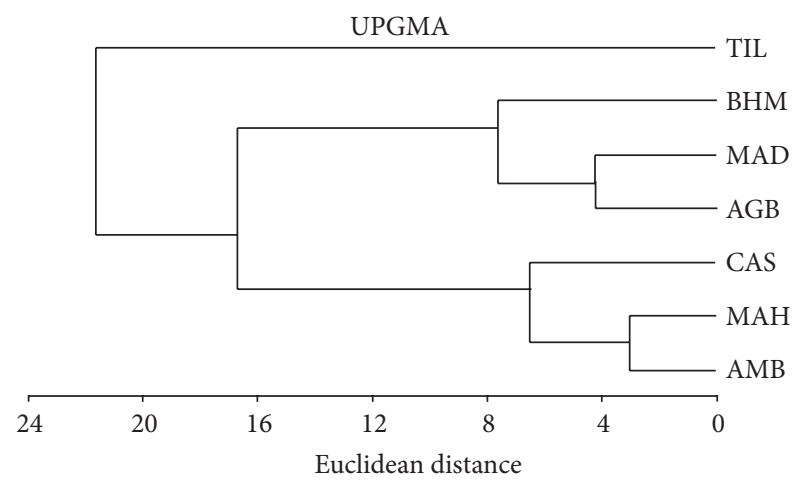

(b)

FIGURE 2: (a) Dendrogram drawn with frequencies of chlorotypes using coefficient of Euclidean distances and UPGMA algorithm. (b) Dendrogram drawn with frequencies of mitotypes using coefficient of Euclidean distances and UPGMA algorithm.

of $57.14 \%$. In all, alleles from 14 loci defined the chlorotypes, while the alleles from 11 loci contributed to the definition of mitotypes.

3.1. Chlorotypes, Mitotypes, and Their Diversity Indices. The seven $S$. racemosa sites were represented by nine chlorotypes (see Supplementary Table 1 in Supplementary Material available online at http://dx.doi.org/10.1155/2014/296891) and eight mitotypes (Supplementary Table 2). The distribution of the haplotypes with respect to geographical locations is presented in Figure 1 and Table 3. No haplotype common to all the sites was detected for both cp and mt DNA but the $\mathrm{CH} 1$ and MT1 haplotypes were dominant haplotypes. AGB represented the highest number of haplotypes for both the genomes while in contrast, TIL was represented by only one $\mathrm{cp}$ and $\mathrm{mt}$ DNA haplotypes each. The number of chlorotypes detected per individual was also the lowest (0.05) for TIL and the highest for AGB (0.55) and MAD (0.60) (Table 3). The situation was similar for the number of mitotypes as well. As clear from Table 3, the diversity was high in the protected group and low in the disturbed group in case of both the genomes.

The diversity indices estimated using HAPLODIV and HAPLONST revealed high total diversity $\left(H_{T}\right)$ for $\mathrm{cp}(0.786)$ and $\mathrm{mt}(0.778)$ genomes, although the intrasites diversity $\left(H_{S}\right)$ was low $(\mathrm{cp}=0.352, \mathrm{mt}=0.245)$. The trends were similar for the ordered counterparts. $V_{T}$ for cp genome is 0.787 and for $\mathrm{mt} 0.769$, and $v_{S}$ for cp is 0.352 and for $\mathrm{mt} 0.312$. Permutation analysis of chlorotypes and mitotypes with 1000 permutations gave $5 \%$ of the permuted values greater than the observed value of $N_{S T}$, indicating that the difference between $G_{S T}$ and $N_{S T}$ was significant. The $G_{S T}^{\prime \prime}$ value was very high ( 0.910 for $\mathrm{cp}$ and 0.954 for $\mathrm{mt}$ ) for both the genomes. Low values of $H_{S}$ lead to low values of $D$ than $G_{S T}$, but practically they appear to be greater than $G_{S T}$ as the within population diversity is high [27]. In our study also for cp genome the value of $D$ was 0.780 and for $m$ t genome 0.823 which is greater than $G_{S T}$.
3.2. Relationships among the Haplotypes. The dendrograms drawn using the UPGMA algorithm considering the frequencies of individual chlorotypes and mitotypes in each population are represented in Figures 2(a) and 2(b). Surprisingly, both the dendrograms were almost similar and showed clustering of the sites as per the geographical locations; the two Maharashtra sites (AMB and MAH) along with the north Karnataka site, CAS, formed one cluster, while the southern Karnataka sites (AGB, MAD, and BHM) formed another cluster. However, the TIL (Maharashtra) separated out from both the clusters in both the dendrograms. The MSN depicting the phylogenetic relationships among the chlorotypes and mitotypes (Figure 3 ) showed the presence of some of the unique haplotypes $(\mathrm{CH} 2, \mathrm{CH} 7$, and $\mathrm{CH} 9$ and MT2 and MT8) in the edges of the tree; while the dominant ones occupied anterior position in the network. In the cpDNA MSN, a maximum of five mutations were observed between $\mathrm{CH} 1$ and $\mathrm{CH} 8$, while, in the mtDNA network, two alternative connections were observed between MT1 and MT5 and MT6 and MT7 (Figure 3).

3.3. AMOVA. The AMOVA performed with all the sites taken together showed that $74.32 \%$ and $69.26 \%$ variation were partitioned among the seven sites for $\mathrm{cp}$ and $\mathrm{mt}$ DNA, respectively, while the rest of the variation was within the populations (Table 4). However, when the AMOVA was performed with the populations grouped according to their ecological status (protected, semiprotected and disturbed), a majority of the variation was partitioned among populations within groups, while the rest of the variation was found within populations and among groups (Table 4).

\section{Discussion}

In the present study, the haplotypes were distributed vis-àvis the geographical distances among them and the genetic diversity was relatively low within sites, similar to that reported for Orobanche glumaepatula [30] and O. cumana 

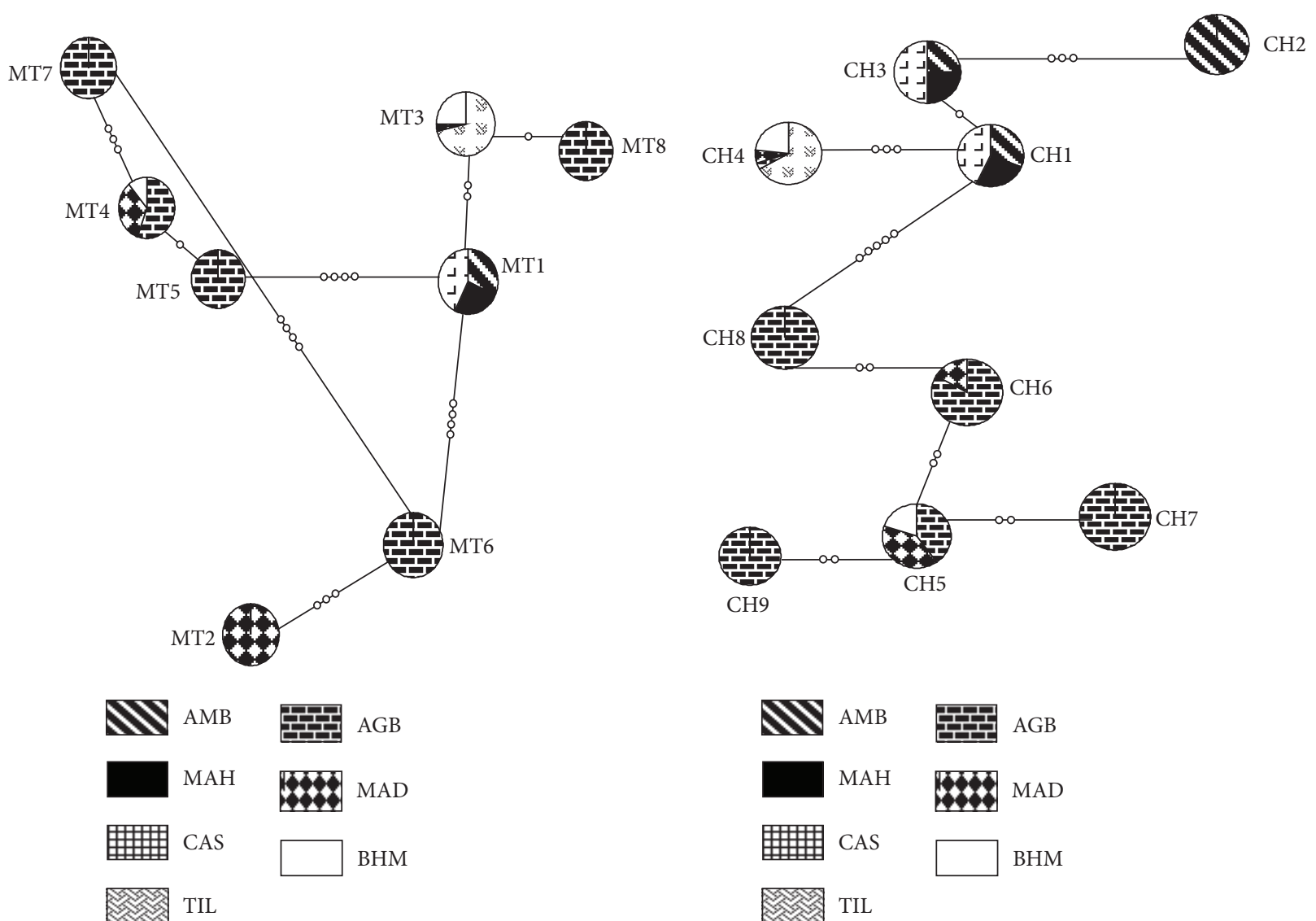

FIgURE 3: Minimum spanning network of S. racemosa showing relationships among the chlorotypes $(\mathrm{CH})$ and mitotypes (MT). The circles in the figure indicate the type of chlorotype and mitotype. The shades within each circle indicate the contribution of each population to the chlorotype and mitotype. The small circles within the lines connecting the circles indicate the number of mutations between the haplotypes.

[31]. The low within-sites diversity might be because of fixation of most of the populations (except the AGB) for one or two types of haplotypes, while the high total diversity observed in this study was probably contributed by the unique haplotypes. Unique haplotypes are characteristic of expanding population and are not known to be found in population where the anthropogenic activities are the highest [32]. The Karnataka sites (AGB, MAD, and BHM) were more diverse, being represented by maximum number of haplotypes, which was apparently contributed by the unique haplotypes, especially in AGB. The TIL site shared one chlorotype and one mitotype with these populations, which are more than $400 \mathrm{~km}$ away from it, indicating that the genetic affinities among the sites were irrespective of the geographical distances. However, after this, TIL site apparently got fixed only for these haplotypes and no other haplotypes were detected even after sampling a maximum number of individuals from this site.

The patchy or fragmented landscape of TIL seems to contribute to isolation of the population, which might have resulted in reduction of genetic diversity in this area. Long lived woody perennials, in particular, are expected to be resilient to changes in genetic diversity due to ample gene flow especially if they are cross-pollinating and have long generation times. However, habitat fragmentation might lead to genetic changes in remnant plant populations, which include the erosion of genetic variability and acceleration of genetic divergence among the populations by means of two mechanisms: reduced gene flow and an increase in random genetic drift, which might be true for the TIL. Due to this, the CAS and TIL sites, though separated by a distance of only $45 \mathrm{~km}$, did not share any common haplotype. This indicated the lack of gene flow between them and underlined the existence of possible barriers in gene flow among these two populations.

Population differentiation is relatively high in both gymnosperms and angiosperms for $\mathrm{cp}$ and $\mathrm{mt}$ DNA, since the genomes are generally maternally inherited [33]. This has been found to be true in the present study as well. Low values of $H_{S}$ (in this study, for cp, $H_{S}=0.352$ and, for $\left.\mathrm{mt}, H_{S}=0.245\right)$ indicate either low mutation rate or a consequence of genetic drift. In our study $D$ is larger than $G_{S T}$ which is because of high within population diversity [27]. This indicates that $G_{S T}$ underestimates the among population differentiation. Significant genetic differentiation in populations of tree species is observed when there is restricted seed and pollen dispersal resulting in low gene flow $[34,35]$ as observed in this study. The lack of haplotype 
sharing along with high differentiation values obtained here implied an ancient nature of the sites. The species, which experience long-term biogeographic barriers to gene flow, are known to be composed of geographical populations that belong to different genealogies and are correlated to geographical boundaries [36]. Most of the sites of S. racemosa were restricted to mountains in small size and were strongly isolated from each other by mountains and valleys, which might have enhanced fragmentation in their habitat. Past fragmentation leading to geographical isolation and limited pollen/seed dispersal among the populations might have resulted in much lower diversity within populations and elevated genetic differentiation among the sites of S. racemosa.

In general, for out-crossing, wind-pollinated, and longlived tree species, genetic variation is expected to be maintained within populations, while predominantly selfing, short-lived species harbor comparatively higher variation among the populations. Although S. racemosa is a perennial out-crossing woody angiosperm, most of the genetic variation in this study was partitioned among the sites. This could be because these sites might have become susceptible to stochastic effects of genetic drift leading to reduction in heterozygosity and loss of alleles. Such lower genetic diversity has also been reported previously in many other relic species of East Asia, for example, Alsophila spinulosa [37], Ammopiptanthus mongolicus, and A. nanus [38]. The genetic distances among the populations analyzed in this study did not correspond to the geographic distances among them. The pattern obtained in the genetic differentiation versus geographical distances indicated the same. Similar observations have been reported by Cronberg [39] and Galeuchet et al. [40] as well.

The high haplotype diversity observed in the protected sites highlights the fact that the genetic variability is higher in protected areas, suggesting a relation between genetic variation and habitat disturbance. The occurrence of only one or two haplotypes in disturbed areas despite the size of the samples being large might imply erosion of genetic variation due to various anthropogenic activities in these areas. In contrast, the presence of relatively high number of haplotypes and, as a result, high diversity in protected and semiprotected areas emphasizes the roles played by various natural factors in maintaining the diversity. The study areas AMB and MAH, which are under high demographic pressures due to various anthropogenic activities and other factors, have already been identified as reserve forests of high conservation value.

The lack of genetic diversity observed in disturbed areas, resulting in reduced fitness of the populations, has been observed in many studies [41]. Such genetic impoverishment is usually assumed to be the effect of genetic erosion within isolated populations in fragmented environments. A variety of conservation approaches ranging from strict protection to alteration of existing land use patterns to targeted management interventions for a particular species would be necessary across these areas for sustainable management of resources in these forests [41]. As the protected areas harbored higher genetic diversity than semiprotected and disturbed areas, these areas need to be strictly protected from human exploitation to conserve the inherent biodiversity.
However, human intervention would be necessary to augment the genetic diversity in semiprotected and disturbed areas by introducing individuals with different haplotypes from protected areas into these areas. In view of this, the AGB population would be a good source of different haplotypes of $S$. racemosa to be introduced in other areas.

\section{Conclusion}

The present study identified $S$. racemosa populations with low diversity as well as with unique haplotypes that could be used for formulating conservation strategies for the species. Among all the populations, the populations from protected areas exhibited high diversity while the disturbed areas showed less diversity. Since the AGB population depicted the highest number of haplotypes for both $\mathrm{cp}$ and $\mathrm{mt}$ genomes, it would be a good source of different haplotypes to be introduced in other areas. However, more such studies entailing other important plants from these biodiversity hotspots are needed to identify the target sites for effective maintenance and conservation of biodiversity of WG.

\section{Conflict of Interests}

The authors declare that there is no conflict of interests regarding the publication of this paper.

\section{Acknowledgments}

The authors thank Dr. Ram Kulkarni (Indian Institute of Science Education and Research, Pune) for the help rendered during sampling and Vivek Gupta (Bharati Vidyapeeth, Pune) for the help rendered during experimentation. The authors are thankful to Dr. Ankur Patwardhan (Abasaheb Garware College, Pune) for his suggestions in classifying the data. They also thank the staff at the various field stations and forest departments for their cooperation in sampling. Sofia Banu thanks the Council of Scientific and Industrial Research (CSIR), India, for research fellowship. This project was supported by a grant from the Department of Biotechnology, India, to NCL and BSI.

\section{References}

[1] N. Myers, R. A. Mittermeler, C. G. Mittermeler, G. A. B. Da Fonseca, and J. Kent, "Biodiversity hotspots for conservation priorities," Nature, vol. 403, no. 6772, pp. 853-858, 2000.

[2] P. Davidar, J. P. Puyravaud, and E. G. Leigh Jr., "Changes in rain forest tree diversity, dominance and rarity across a seasonality gradient in the Western Ghats, India," Journal of Biogeography, vol. 32, no. 3, pp. 493-501, 2005.

[3] R. P. Cincotta, J. Wisnewski, and R. Engelman, "Human population in the biodiversity hotspots," Nature, vol. 404, no. 6781, pp. 990-992, 2000.

[4] S. Wright, "Evolution in Mendelian populations," Genetics, vol. 16, no. 2, pp. 97-159, 1931.

[5] J. L. Hamrick and M. J. W. Godt, "Conservation genetics of endemic plant species," in Conservation Genetics, J. C. Avise and 
J. L. Hamrick, Eds., pp. 281-304, Chapman and Hall, New York, NY, USA, 1996.

[6] J. Dong and D. B. Wagner, "Paternally inherited chloroplast polymorphism in pinus: estimation of diversity and population subdivision, and tests of disequilibrium with a maternally inherited mitochondrial polymorphism," Genetics, vol. 136, no. 3, pp. 1187-1194, 1994.

[7] B. J. Furman, W. S. Dvorak, R. R. Sederoff, and D. M. O’Malley, "Molecular markers as diagnostic tools to identify species, hybrids and introgression: a study of Central American and Mexican pines," in Proceedings of the OFRI IUFRO Conference of the Tree Improvement for Sustainable Tropical Forestry, M. J. Dieters, A. C. Matheson, D. G. Nikles, C. E. Harwood, and S. M. Walker, Eds., pp. 485-491, Queensland, Australia, 1996.

[8] K. H. Wolfe, W. H. Li, and P. M. Sharp, "Rates of nucleotide substitution vary greatly among plant mitochondrial, chloroplast, and nuclear DNAs," Proceedings of the National Academy of Sciences of the United States of America, vol. 84, no. 24, pp. 9054-9058, 1987.

[9] A. H. D. Brown and D. J. Schoen, "Plant population genetic structure and genetic conservation," in Biodiversity for Sustainable Development, O. T. Sandlund, K. Hindar, and A. H. D. Brown, Eds., pp. 88-104, Scandinavian University Press, Oslo, Norway, 1992.

[10] U. M. Csaikl, K. Burg, S. Fineschi, A. O. König, G. Mátyás, and R. J. Petit, "Chloroplast DNA variation of white oaks in the alpine region," Forest Ecology and Management, vol. 156, no. 1-3, pp. 131-145, 2002.

[11] V. U. Ahmad, M. Zubair, M. A. Abbasi et al., "Structure determination of bioactive galloyl derivatives by NMR spectroscopy," Magnetic Resonance in Chemistry, vol. 43, no. 6, pp. 486-488, 2005.

[12] B. G. Kulkarni, Flora of Sindhudurg, vol. 3 of Flora of India, 1988.

[13] V. U. Ahmad, M. A. Abbasi, H. Hussain et al., "Phenolic glycosides from Symplocos racemosa: natural inhibitors of phosphodiesterase I," Phytochemistry, vol. 63, no. 2, pp. 217-220, 2003.

[14] M. I. Choudhary, N. Fatima, M. A. Abbasi, S. Jalil, V. U. Ahmad, and Atta-ur-Rahman, "Phosphodiesterase-inhibiting glycosides from Symplocos racemosa," Bioorganic and Medicinal Chemistry, vol. 12, article 5793, 2004.

[15] H. Nybom and I. V. Bartish, "Effects of life history traits and sampling strategies on genetic diversity estimates obtained with RAPD markers in plants," Perspectives in Plant Ecology, Evolution and Systematics, vol. 3, no. 2, pp. 93-114, 2000.

[16] E. Richards, M. Reichardt, and S. Rogers, "UNIT 2.3: preparation of genomic DNA from plant tissues," in Current Protocols in Molecular Biology, M. Ausubel, Ed., pp. 2.3.1-2.3.7, John Wiley and Sons, New York, NY, USA, 1994.

[17] B. Demesure, N. Sodzi, and R. J. Petit, "A set of universal primers for amplification of polymorphic non-coding regions of mitochondrial and chloroplast DNA in plants," Molecular Ecology, vol. 4, no. 1, pp. 129-131, 1995.

[18] S. Dumolin-Lapegue, M.-H. Pemonge, and R. J. Petit, "An enlarged set of consensus primers for the study of organelle DNA in plants," Molecular Ecology, vol. 6, no. 4, pp. 393-397, 1997.

[19] T.-Y. Chiang, B. A. Schaal, and C.-I. Peng, "Universal primers for amplification and sequencing a noncoding spacer between the atpB and rbcL genes of chloroplast DNA," Botanical Bulletin of Academia Sinica, vol. 39, no. 4, pp. 245-250, 1998.
[20] O. Pons and R. J. Petit, "Estimation, variance and optimal sampling of gene diversity. 1. Haploid locus," Theoretical and Applied Genetics, vol. 90, no. 3-4, pp. 462-470, 1995.

[21] O. Pons and R. J. Petit, "Measuring and testing genetic differentiation with ordered versus unordered alleles," Genetics, vol. 144, no. 3, pp. 1237-1245, 1996.

[22] P. W. Hedrick, "A standardized genetic differentiation measure," Evolution, vol. 59, no. 8, pp. 1633-1638, 2005.

[23] S. Hagell, A. V. Whipple, and C. L. Chambers, "Population genetic patterns among social groups of the endangered Central American spider monkey (Ateles geoffroyi) in a humandominated landscape," Ecology and Evolution, vol. 3, no. 5, pp. 1388-1399, 2013.

[24] M. Nei, "Analysis of gene diversity in subdivided populations," Proceedings of the National Academy of Sciences of the United States of America, vol. 70, no. 12, pp. 3321-3323, 1973.

[25] M. Nei, "F-statistics and analysis of gene diversity in subdivided populations," Annals of Human Genetics, vol. 41, no. 2, pp. 225 233, 1977.

[26] P. W. Hedrick, "Perspective: highly variable loci and their interpretation in evolution and conservation," Evolution, vol. 53, no. 2, pp. 313-318, 1999.

[27] P. G. Meirmans and P. W. Hedrick, "Assessing population structure: $F_{S T}$ and related measures," Molecular Ecology Resources, vol. 11, no. 1, pp. 5-18, 2011.

[28] L. Excoffier, G. Laval, and S. Schneider, "Arlequin ver. 3.0: an integrated software package for population genetics data analysis," Evolutionary Bioinformatics Online, vol. 1, pp. 47-50, 2005.

[29] R. D.m.page, "TreeView: an application to display phylogenetic trees on personal computers," Computer Applications in the Biosciences, vol. 12, no. 4, pp. 357-358, 1996.

[30] G. S. C. Buso, P. H. Rangel, and M. E. Ferreira, "Analysis of genetic variability of South American wild rice populations (Oryza glumaepatula) with isozymes and RAPD markers," Molecular Ecology, vol. 7, no. 1, pp. 107-117, 1998.

[31] G. Gagne, P. Roeckel-Drevet, B. Grezes-Besset et al., "Study of the variability and evolution of Orobanche cumana populations infesting sunflower in different European countries," Theoretical and Applied Genetics, vol. 96, no. 8, pp. 1216-1222, 1998.

[32] M. Bajc, M. Čas, D. Ballian et al., "Genetic differentiation of the Western Capercaillie highlights the importance of SouthEastern Europe for understanding the species phylogeography," PLoS ONE, vol. 6, no. 8, Article ID e23602, 2011.

[33] B. Demesure, B. Comps, and R. J. Petit, "Chloroplast DNA phylogeography of the common beech (Fagus sylvatica L.) in Europe," Evolution, vol. 50, no. 6, pp. 2515-2520, 1996.

[34] S. Cavers, B. Degen, H. Caron et al., "Optimal sampling strategy for estimation of spatial genetic structure in tree populations," Heredity, vol. 95, no. 4, pp. 281-289, 2005.

[35] O. J. Hardy, L. Maggia, E. Bandou et al., "Fine-scale genetic structure and gene dispersal inferences in 10 Neotropical tree species," Molecular Ecology, vol. 15, no. 2, pp. 559-571, 2006.

[36] J. C. Avise, Molecular Markers, Natural History and Evolution, Kluver Academic, Chapman and Hall, New York, NY, USA, 1994.

[37] T. Wang, Y.-J. Su, X.-Y. Li, B. Zheng, G.-P. Chen, and Q.-L. Zeng, "Genetic structure and variation in the relict populations of Alsophila spinulosa from southern China based on RAPD markers and cpDNA atpB-rbcL sequence data," Hereditas, vol. 140, no. 1, pp. 8-17, 2004. 
[38] X. J. Ge, M. H. Liu, W. K. Wang, B. A. Schaal, and T. Y. Chiang, "Population structure of wild bananas, Musa balbisiana, in China determined by SSR fingerprinting and cpDNA PCRRFLP," Molecular Ecology, vol. 14, no. 4, pp. 933-944, 2005.

[39] N. Cronberg, "Colonization dynamics of the clonal moss Hylocomium splendens on islands in a Baltic land uplift area: reproduction, genet distribution and genetic variation," Journal of Ecology, vol. 90, no. 6, pp. 925-935, 2002.

[40] D. J. Galeuchet, C. Perret, and M. Fischer, "Microsatellite variation and structure of 28 populations of the common wetland plant, Lychnis flos-cuculi L., in a fragmented landscape," Molecular Ecology, vol. 14, no. 4, pp. 991-1000, 2005.

[41] M. Fischer and D. Matthies, "RAPD variation in relation to population size and plant fitness in the rare Gentianella germanica (Gentianaceae)," American Journal of Botany, vol. 85, no. 6, pp. 811-819, 1998. 

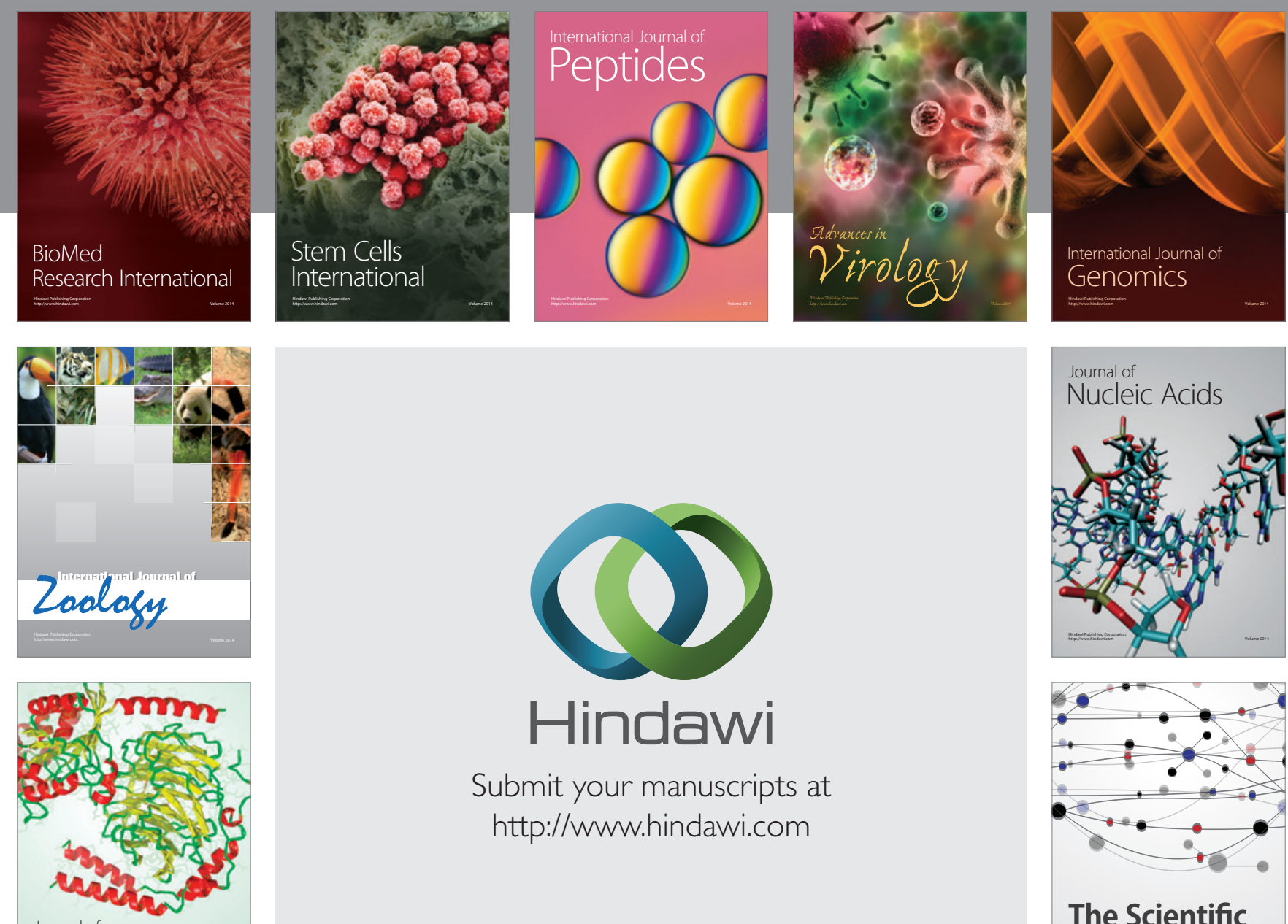

Submit your manuscripts at

http://www.hindawi.com

Journal of
Signal Transduction
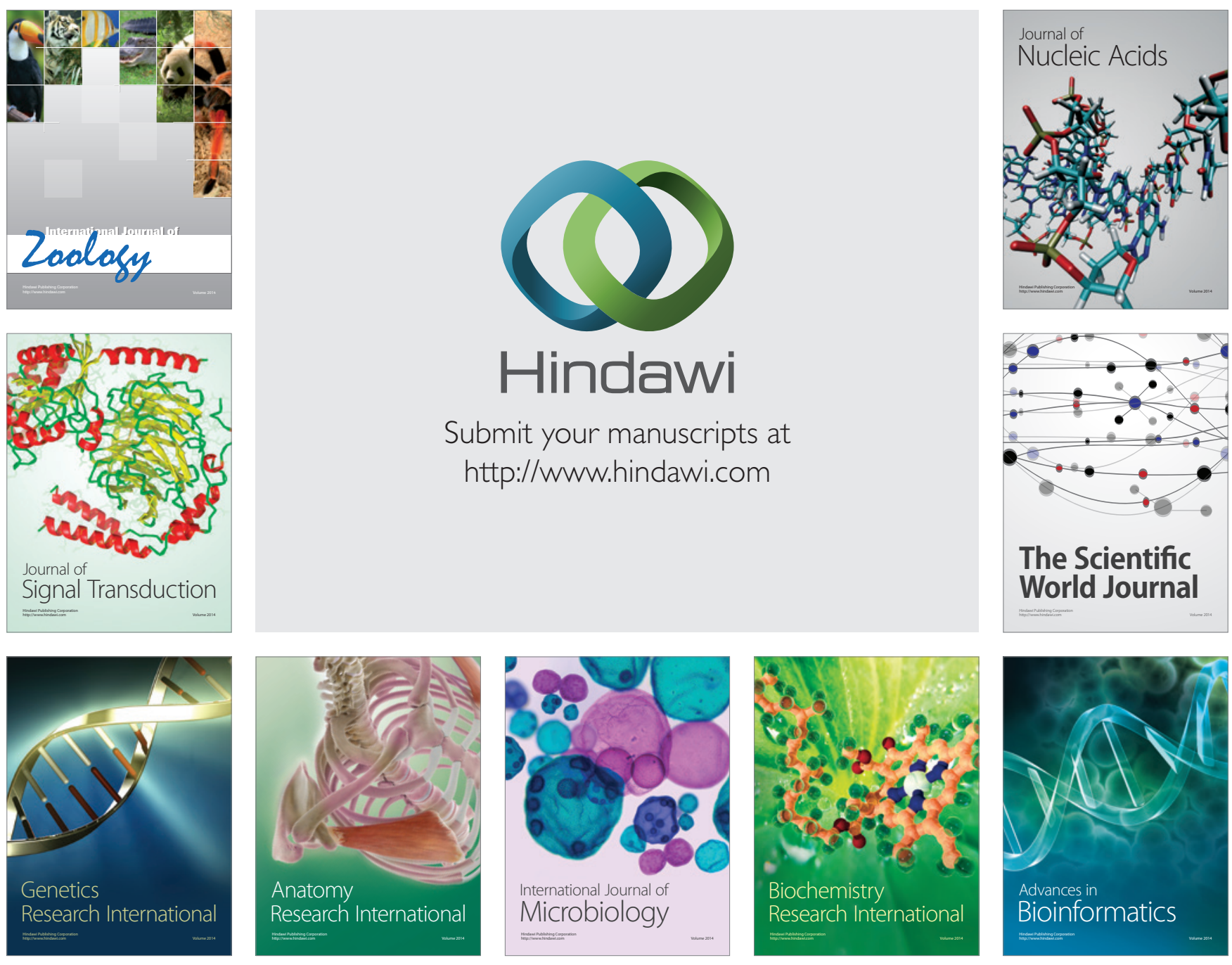

The Scientific World Journal
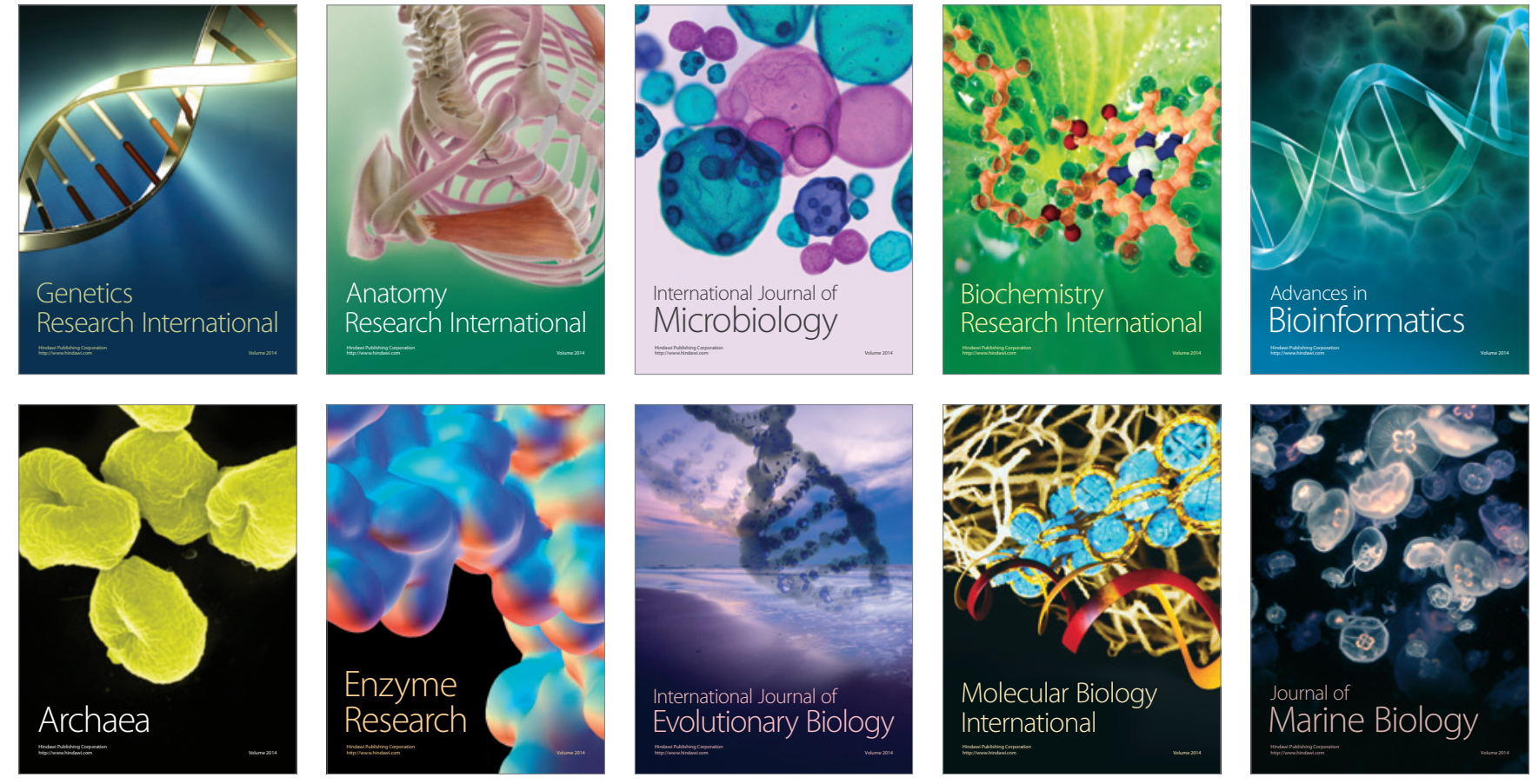